\title{
Postoperative renal cortical necrosis in a patient with contralateral remnant kidney
}

\author{
Seong Kwon Ma, Soo Wan Kim \\ Department of Internal Medicine, Chonnam National University Medical School, Gwangju, Korea
}

A 58-year-old woman was referred to nephrology department because acute kidney injury had developed after left hemicolectomy and partial ureterectomy due to left ureterocolic fistula with ureteral stone. She had a history of left partial nephrectomy because of traumatic renal injury thirty seven years ago. Her baseline serum creatinine level was $0.9 \mathrm{mg} / \mathrm{dL}$. Two days after the operation, serum creatinine level had increased to $2.1 \mathrm{mg} / \mathrm{dL}$ with oliguria. Contrast-enhanced abdominal computed tomography (CT) showed decreased perfusion in right renal cortex sparing medulla, which is the characteristic finding of renal cortical necrosis (Figure-1). Her renal function did not recover although emergency hemodialysis with conservative manage- ment was performed. She has undergone maintenance hemodialysis.

Renal cortical necrosis is a rare cause of acute kidney injury, which is caused by decreased renal arterial perfusion. Obstetric complications remain the leading cause of renal cortical necrosis (1). Non-obstetric causes such as sepsis, hemolytic uremic syndrome and operative procedures are also important causes (2). Contrast-enhanced CT is the useful diagnostic tool although definitive diagnosis is made by renal biopsy (3). It has been suggested that characteristic CT finding is attributed to the selective involvement of interlobular and afferent arterioles (4). Untreated patients have high mortality, and early dialysis is important to improving clinical outcomes (5).

Figure 1 - Axial (A) and coronal scan (B) of contrast-enhanced abdominal computed tomography showed non-enhancement of cortex but enhancement of medulla in right kidney, which is the characteristic finding of renal cortical necrosis.
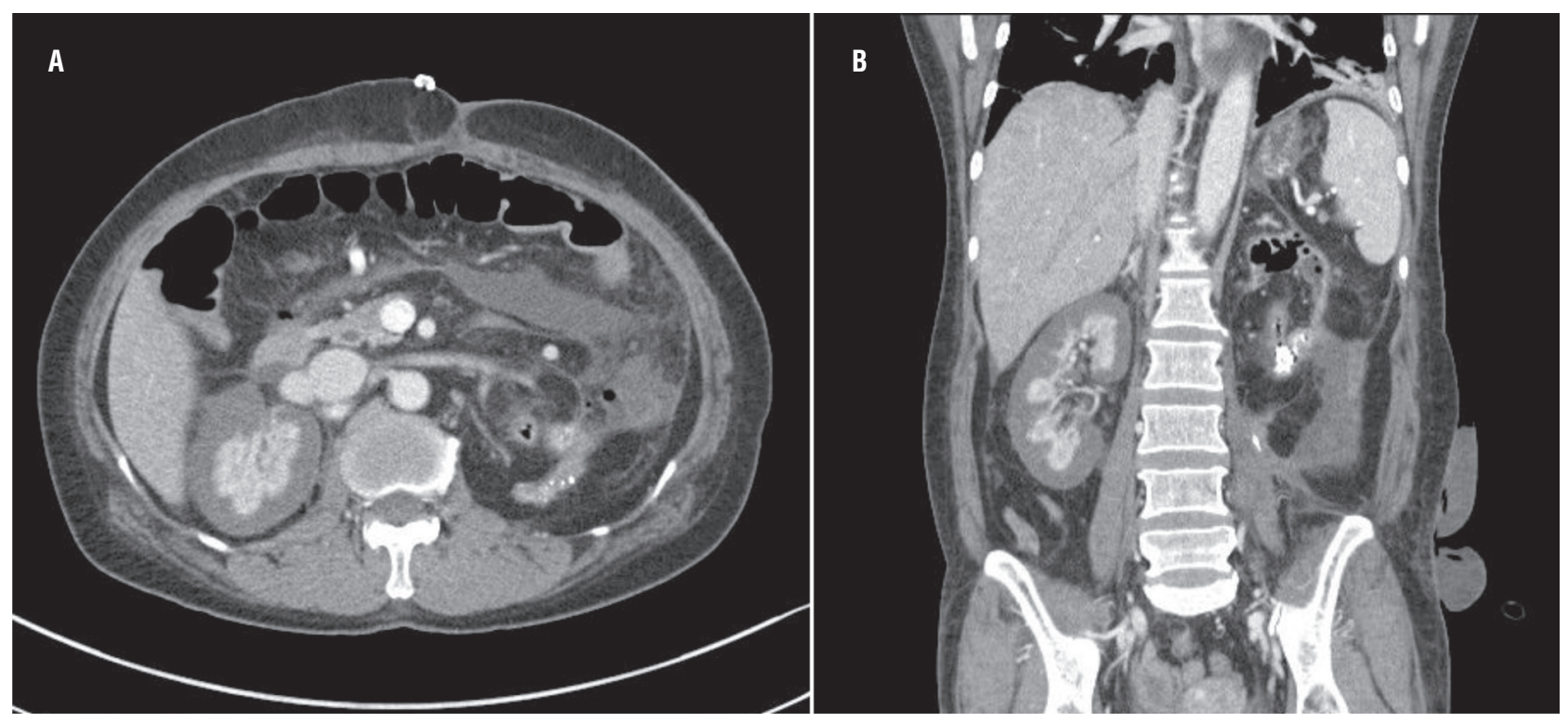


\section{REFERENCES}

1. Kim HJ: Bilateral renal cortical necrosis with the changes in clinical features over the past 15 years (1980-1995). J Korean Med Sci. 1995; 10: 132-41.

2. Hida M, Saitoh H, Satoh T: Autopsy findings in postoperative acute renal failure patients, collected from the annuals of pathological autopsy cases in Japan. Tokai J Exp Clin Med. 1984; 9: 349-55.

3. Kim HJ, Cho OK: CT scan as an important diagnostic tool in the initial phase of diffuse bilateral renal cortical necrosis. Clin Nephrol. 1996; 45: 125-30.
4. Deutsch V, Frankl O, Drory Y, Eliahou H, Braf ZF: Bilateral renal cortical necrosis with survival through the acute phase with a note on the value of selective nephroangiography. Am J Med. 1971; 50: 828-34.

5. Prakash J, Vohra R, Wani IA, Murthy AS, Srivastva PK, Tripathi $\mathrm{K}$, et al.: Decreasing incidence of renal cortical necrosis in patients with acute renal failure in developing countries: a single-centre experience of 22 years from Eastern India. Nephrol Dial Transplant. 2007; 22: 1213-7.

Correspondence address:

Soo Wan Kim, MD

Department of Internal Medicine, Chonnam National University Medical School 42 Jebong-ro, Dongku, Gwangju 501-757, Korea

Fax: +82-62-2258578

E-mail: skimw@chonnam.ac.kr

ARTICLE INFO

Int Braz J Urol. 2014; 40:429-30

Submitted for publication: August 06, 2013

Accepted after revision: January 09, 2014 